EESTI NSV TEADUSTE AKADEEMIA TOIMETISED. VII KÖIDE

BIOLOOGILINE SEERIA. 1958, NR. 2

ИЗВЕСТИЯ АҚАДЕМИИ НАУК ЭСТОНСКОИ ССР. ТОМ VII

СЕРИЯ БИОЛОГИЧЕСКАЯ. 1958, №2 2

\title{
ANDMEID GLOEOTRICHIA J. AG. LIIKIDE ARENEMISJÄRKUDEST SEOSES LIIGI OSCILLATORIA LACUSTRIS (KLEB.) GEITL. SUSTEMAATILISE KUULUVUSEGA
}

\section{E. KUKK}

Sinivetikate perekonda Gloeotrichia tuntakse iseseisva perekonnana juba üle 100 aasta (eraldatud 1842. aastal J. Agardh'i poolt). Tema liigid on üsna laialdaselt levinud, mitmed neist on isegi kosmopoliidid. Tänu heale kasvule kultuuris on nad olnud mitmete autorite uurimisobjektiks (de Bary, 1863; Beck, 1886; Schwendener, 1894; Teodoresco, 1907; Полянский, 1930; Горбунова, 1949, 1950).

Et selgitada mõningaid spooride kujunemisega seotud küsimusi, seadsime 1955. a. novembris üles kolvid Gloeotrichia pisum'i kultuuridega. Toitelahusena kasutasime Danilovi toitelahust (Голлербах ја Полянский, 1951, lk. 178). Kultuuride lähtematerjaliks võtsime Vaskna järvest (Võru raj.) jää alt Gloeotrichia pisum'i kolooniaid koos substraadiga (Equisetum limosum'i varretükid).

Pärast kümnepäevast viibimist pidevas valgustuses $+16^{\circ}-+19,6^{\circ} \mathrm{C}$ temperatuuris hakkasid kolooniad rohelisemaks muutuma, mis oli nähtav paljale silmalegi. Mikroskoopilisel vaatlusel selgus, et spooride tume, tavaliselt kollakasroheline sisu oli muutunud peaaegu mustaks ning teraliseks ja eemaldunud spoori kestast. Spooride sisus olid tekkinud gaasivakuoolid. Paljudest spooridest aga oli sisu kesta distaalse otsa limastumisel väljunud. Samaaegselt ilmusid kultuuri toitelahusesse omapänased vabalt ujuvad, omavahel enam-vähem paralleelse asetusega niitide kimbud, millede üksikud niidid olid üsna sarnased idanevate spooridega, kuid väga lühikeste rakkudega, mis vaheseinte kohal olid tugevasti sisse soonistunud. Niitide laius kōikus enamasti $5-7 \mu$ (harva kuni $9 \mu$ ) piirides, nende rakkude kuju aga varieerus suuresti. Viimaste pikkus kõikus tavaliselt $2-8 \mu$ (harva kuni $12 \mu$ ) piirides. Rakkude soonistus vaheseinte kohal oli mõnikord vähemärgatav, sageli aga nii tugev, et üksikud vegetatiivsed rakud näisid peaaegu ümmargustena. Eriti muutliku kuju ja sisaldisega olid niitide otsmised rakud: mõnel juhul sarnanesid nad kuju ja suuruse poolest täiesti niidi teiste rakkudega; mõnikord olid nad veidi laiemad, sageli aga poole kitsamad teistest, kuid viimasel juhul kuni $13 \mu$ pikad. Rakkude sisu varieerus täiesti värvitust ja homogeensest kuni tüüpilise tumeda teralise massini.

Kõnesolevad niitide kimbud olid väga sarnased 1955. aasta varasuvel Murati järve (Vastseliina raj.) litoraali planktonist kogutud materjaliga, mille olime määranud liigiks Oscillatoria lacustris (Kleb.) Geitler (sünonüüm Trichodesmium lacustre Kleb.). Nimetatud proovis esinesid umbes $2 \mathrm{~mm}$ pikkused ja $1 \mathrm{~mm}$ laiused soomusjad moodustised, mis samuti koosnesid paralleelselt asetunud $7 \mu$ laiustest niitidest. Enamik niitide rakke oli 
tünja kujuga ja tavaliselt võrdse pikkuse ning laiusega. Oma sisemuses esinevate vakuoolide tõttu näisid nad peaaegu mustadena. Otsmised rakud aga olid kuni 2 korda pikemad laiusest ja paistsid olevat sisaldiseta.

Oscillatoria lacustris'e ja perekond Gloeotrichia liikide leviku ja arengu kohta leiduva kirjanduse süstemaatilisel läbitöötamisel selgus meile, et kogu NSV Liidu territooriumil märgitud kaheksateistkümnest $O$. lacustris'e leiukohast esines kolmeteistkümnes ka kas üks või mitu Gloeotrichia perekonna esindajat. Viiest $O$. lacustris'e leiukohast pole leitud perekond Gloeotrichia esindajaid. Neist ühest leiukohast (vt. tabelist: Voronihhin, 1935) on materjalid kogutud juulis, seega vegetatsiooniperioodi I poolel, millal Gloeotrichia'l spoore veel ei esine (isegi meie tingimustes). Näib, et autor on pidanud spoorideta materjali perekond Rivularia liigiks (Воронихин, 1935, lk. 114: Rivularia sp.).

\begin{tabular}{|c|c|c|c|c|c|}
\hline \multirow[b]{3}{*}{ Autor } & \multicolumn{5}{|c|}{ Leiud } \\
\hline & \multirow{2}{*}{ 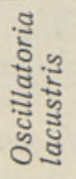 } & \multicolumn{4}{|c|}{ Gloeotrichia } \\
\hline & & pisum & natans & $\begin{array}{l}\text { echi- } \\
\text { nulata }\end{array}$ & $\begin{array}{l}\text { inter- } \\
\text { media }\end{array}$ \\
\hline Ivanov, L. A. (1899) & + & + & + & - & - \\
\hline Ivanov, L. A. (1901) & + & - & - & + & - \\
\hline Meier, K. I. (1922) & + & - & - & + & - \\
\hline Meier, K. I. ja & & & & & \\
\hline Reinhardt, L. V. (1925) & $\begin{array}{l}+ \\
+\end{array}$ & $\begin{array}{l}+ \\
+\end{array}$ & $\begin{array}{l}+ \\
-\end{array}$ & $\begin{array}{l}+ \\
-\end{array}$ & - \\
\hline Meier, K. I. (1930) & + & + & + & + & - \\
\hline Skorbatov, L. A. (1926) & + & - & - & - & + \\
\hline $\begin{array}{l}\text { Stroganov, S. N. ja } \\
\text { Zahharov, N. G. (1927) }\end{array}$ & + & + & + & + & + \\
\hline Kisseljov, I. A. (1931a) & + & - & + & - & - \\
\hline Kisseljov, I. A. (1931b) & + & - & + & - & - \\
\hline Poljanski, V. I. (1935) & + & - & - & - & - \\
\hline $\begin{array}{l}\text { Skuja, H. (1926): } \\
\text { seisvates vetes Liepaja }\end{array}$ & & & & & \\
\hline lähedal & + & - & + & - & + \\
\hline Usma järv & + & + & + & + & - \\
\hline Väike-Kanieri järv & + & - & - & - & - \\
\hline Riia Viesturpargi tiik & + & - & - & - & - \\
\hline Sidrabezers & + & - & - & - & + \\
\hline Baltezers & + & - & - & - & - \\
\hline Voronihhin, N. N. (1935) & + & - & - & - & - \\
\hline
\end{tabular}

Ưlejäänud neljast leiukohast (Skuja, 1926; Полянский, 1935) on kogutud ja uuritud ainult planktonit, kuid perekond Gloeotrichia liikidest on tüüpiline planktoniliik üksnes Gl. echinulata. Analoogilisi andmeid saime ka meil kasutada olnud välismaistest floristilistest töödest (Klebahn, 1895; Smith, 1920; Järnefelt, 1956).

Olles veendunud Oscillatoria lacustris'e ja perekond Gloeotrichia liikide omavahelises seoses, rajasime 1957. a. veebruaris uued Gloeotrichia pisum'i kultuurid (mitmest erinevast veekogust pärineva materjaliga), mida hakkasime juba süstemaatiliselt jälgima. Selgus, et idanenud ja kestast väljunud spoorid (nimetame neid èdaspidi sporohormogoonideks) muutusid oma arenemiskäigus selliselt, et meil õnnestus kultuurides näha kõiki Oscillatoria lacustris'e erikujusid, mida on kirjeldatud seni ilmunud kirjanduses. 
Juba Klebahni tööst (1895) võib näha, et Oscillatoria lacustris'e (sünonüüm Trichodesmium lacustre) süstemaatiline kuuluvus on olnud problemaatiline. Klebahn kirjutab (lk. 271-273): «Välisilmelt on Trichodesmium ja Aphanizomenon täiesti sarnased. Raskusi valmistab aga see, et esimesel pole senini leitud heterotsüste ja et tema rakud pole nagu Aphanizomenon flos-aquae'l silinderjad, vaid sageli kerajad. Olen tema (s. t. Oscillatoria lasustris'e - E. K.) ühendanud heterotsüstideta perekonnaga Trichodesmium, kus senini on tuntud aga ainult mariinsed vormid, mis paljude tunnuste poolest siiski erinevad kõnesolevast vetikast.» Samas märgib ta veel, et: «... olen kahjuks sellises olukorras, et ei saa anda sellele liigile kindlat kohta süsteemis.» Nagu muuseas mainib Klebahn, et tema sõber O. Zacharias peab kirjeldatud materjali Gloeotrichia echinulata arenemisstaadiumiks.

Lemmermanni (1910, 1k. 117) arvates on Trichodesmium lacustre, tänu kitsamate tipurakkude esinemisele, palju lähedasem perekonnale Aphanizomenon. Tipurakkude kujust lähtudes eraldab Nygaard (1926, lk. 221-222) Ivanovi poolt (1901, lk. 388) Trichodesmium lacustre'ks määratud materjali pōhjal koguni uue liigi - Trichodesmium Iwanoffianum Nyg. Kisseljov (1927, lk. 280) märgib Araali mere vetikaid käsitlevas töös, et Ostenfeld (1908, lk. 123-225) on seal esinevat Oscillatoria lacustris't pidanud arvatavasti perekond Nodularia liigiks.

Võrreldes Nygaard'i liiki Trichodesmium Iwanoffianum'it (joon. 3, 4) Klebahni Trichodesmium lacustre (joon. 5, 6, 7) ning Smith'i (joon. 1) ja J. K. Kossinskaja (Jelenkin, 1949, lk. 1305, joon. 396; siin joon. 8) Oscillatoria lacustris'e joonistega näeme, et Klebahni ja Kossinskaja joonistel on niitide rakud (peale tipurakkude) täiesti sarnased. Erinevus on vaid tipurakkude kujus. Nygaard'i ja Smith'i joonistel ilmneb vahe üksnes rakkude pikkuses. Kultuuris arenenud sporohormogoonide muutuste pōhjal reastuvad eespool mainitud autorite poolt kirjeldatud ja joonistel kujutatud materjalid

Joon. 1. Kimp sporohormogoone (tugevasti suurendatult, Smith'i järgi); üksikutes niitides on näha heledamaid, pooldumist algavaid rakke.

Рис. 1. Пучок спорогормогониев. Некоторые спорогормогонии с бледными, начинающими делиться клетками (сильное увеличение; по Смису).

Fig. 1. Das Bündel der Sporohormogonien (stark vergrössert, nach Smith). Die blassen Zellen in den Sporohormogonien stehen unmittelbar vor der Zellteilung.

Joon. 2. Sporohormogoonid kultuurist, neist parempoolne poolduvate rakkudega.

Рис. 2. Спорогормогонии из культуры. Правый из них - с клетками, находящимися в состоянии деления.

Fig. 2. In der Kultur gezüchtete Sporohormogonien. Rechts Sporohormogonium mit den sich teilenden Zeilen.

Joon. 3. Hiljuti kestast väljunud sporohormogoonide kimp (Nygaard'i järgi).

Рис. 3. Пучок спорогормогониев, только что вышедших из влагалищ (по Ньюго).

Fıg. 3. Das Bündeı der vor kurzem aus den Scheiden ausgetretenen Sporohormogonien (nach Nygaard).

Joon. 4 ja 7. Sporohormogoonide kimbud (väikesel suurendusel; Nygaard'i ja Klebahni järgi).

Рис. 4 и 7. 1уучки гормогониев (слабое увеличение; по Ньюго и Қлебану).

Fig. 4 und 7. Die Bündel der Sporohormogonien (kleine Vergrösserung; nach Nygaard und Klebahn).

Joon. 5 ja 6 . Niidiks diferentseeruvad sporohormogoonid (Klebahni järgi).

Рис. 5 и 6. Спорогормогонии, превращающиеся в типичную нить (по Клебану).

Fig. 5 und 6. Die Sporohormogonien, die sich schon in die typische Gloeotrichia-Trichome umgestalten (nach Klebahn).

Joon. 8. Uksikult esinevad sporohormogoonid (Kossinskaja järgi).

Рис. 8. Одиночные спорогормогонии (по Косинской).

Fig. 8. Einzelne Sporohormogonien (nach Kossinskaja). 


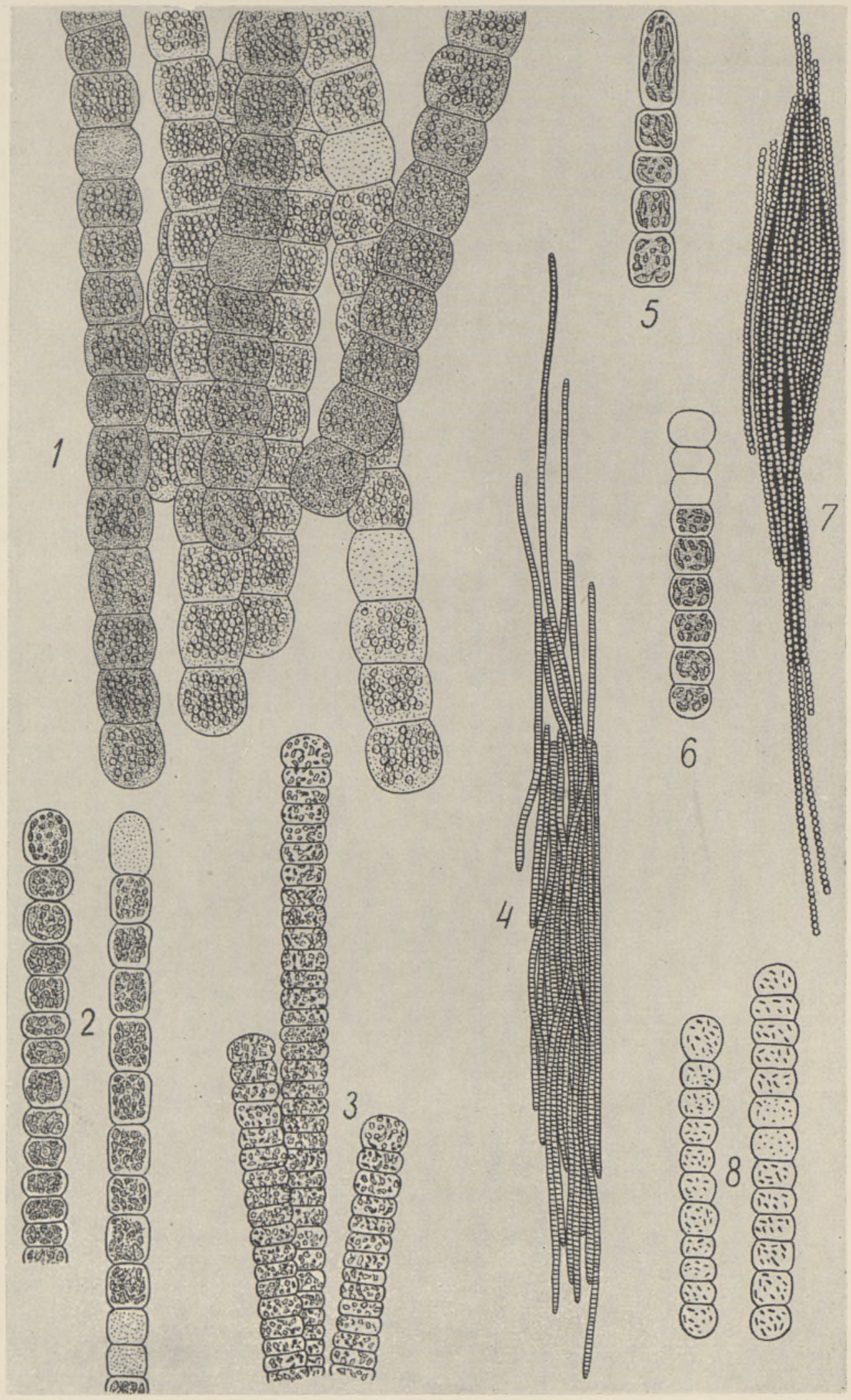


järgmiselt: kõige nooremaid, vahetult kestast väljunud sporohormogoone kujutab oma joonisel Nygaard. Rakud on seal kõik ühtlase sisuga ja nende pikkus on laiusest märgatavalt lühem. Järgmise astme moodustraks Smith’i ja Kossinskaja poolt kirjeldatud materjal, kus kõik niidi rakud on veel võrdse laiusega ja enam-vähem ühepikkused. Mõnikord esineb niidis üksikuid heledama sisaldisega rakke (joon. 1), mis on pooldumist algavad rakud. Rakkude pooldumisele eelneb gaasivakuoolide kadumine neis. Klebahni joonisel on toodud niidid, milledel hakkavad juba diferentseeruma alus ja tipp. Tipurakud muutuvad teistest niidi rakkudest märgatavalt kitsamaks ja pikemaks. Ka väheneb rakkudes gaasivakuoolide hulk.

De Bary' (1863, 1k. 577-588), Schwendeneri (1894) ja Gorbunova (1949, 1950) töödest selgub, et Gloeotrichia pisum'i, Gl. natans'i, Gl. echinulata ja Gl. intermedia sporohormogoonid on kestast väljumise momendil alati gaasivakuoolidega ja võivad esineda nii kimpudena kui ka üksikult. Sporohormogoonid jagunevad teatavas ajavahemikus (mõne minuti kuni ühe nädala vältel) paljudeks lühikesteks osadeks (samal ajal rakkude pooldumist ei toimu). Gaasivakuoolid võivad kaduda juba parikümne tunni jooksul. Rakkude diferentseerumine niidis võib alata juba paar tundi pärast sporohormogoonide jagunemist. Gloeotrichia pisum'il tekib sel puhul kohe sporohormogoonist või selle tükist asümmeetriline niit; Gloeotrichia echinulata'l aga sporohormogooni või selle osa mõlemad otsad esialgu ahenevad ja jagunemine kaheks asümmeetriliseks niidiks toimub alles hiljem.

Nagu eespooltoodust näeme, muutuvad kestast väljunud sporohormogoonid lühikese aja vältel tunduvalt ja kogu Gloeotrichia perekonna esindajatel enam-vähem sarnaselt. Erinevused ilmnevad kõige hilisemates arenemisstaadiumides. Sporohormogoonide kiire muutumine arvatavasti ongi põhjustanud paljude erinevate vormide kirjeldamise. Jelenkin (1949, 1k. 1309), püüdes leida seletust paljude erinevate seisukohtade esinemisele Oscillatoria lacustris'e morfoloogias ja bioloogias, tuleb veendumusele, et «... Oscillatoria lacustris on erakordselt polümorfne, palju pisivorme sisaldav liik, millel võib igas erinevas leiukohas esineda see või teine väga mitmekesiselt varieeruv tunnuste kombinatsioon.»

Lähtudes aga nii kultuuridel tehtud tähelepariekuist kui ka eespool nimetatud kirjandusest võib üsna kindlalt kinnitada, et senini iseseisva liigina kirjeldatud Oscillatoria lacustris (Kleb.) Geitl. (sünonüümid Trichodesmium lacustre Kleb.; Trichodesmium Iwanoffianum Nyg.; Skujaella lacustris (Kleb.) Gius de Toni) pole midagi muud kui perekond Gloeotrichia mõne lijgi või liikide sporohormogoonid, mida on kirjeldatud pärast kestadest. väljumist. Hilisemad vaatlused ja võrdlused mitmete liikide kultuurides selgitavad, milliseid muutusi teevad läbi erinevate liikide sporohormogoonid samadel arenemisastmetel.

\section{KIRJANDUS}

De B a ry, A, 1863. Beitrag zur Kenntnis der Nostocaceen, insbesondere der Rivularien. Flora od. Allg. Bot. Zeitung, N. R. XXI (XLVI). Regensburg.

B eck, G., 1886. Hormogonienbildung von Gloictrichia natans Thur. Verh. Z.-Bot. Ges. in Wien, Bd. XXXVI. Wien.

Järn ef e $1 \mathrm{t}$, H., 1956. Zur Limnologie einiger Gewässer Finlands, XVII. Ann. Zool. Soc. «Vanamo», 17, 1. Helsingforsiae.

K l e b a h n, H., 1895. Gasvakuolen, ein Bestandteil der Zellen der Wasserblüte bildenden Phycochromaceen. Flora od. Allg. Bot. Zeitung, 80. Regensburg.

L e m m e r m a n n, E., 1910. Algen I. Kryptogamenflora d. Mark Brandenburg, 3. Leipzig.

Ny g a a r d, G.; 1926. Plankton from two lakes of Malayan region. Videnskab. Meddelelser Dansk nat.-hist. For., Bd. 82. København. 
Ostenfeld, C., 1908. The Phytoplankton of the Aral Sea. Wiss. Ergebn. der AralseeExpedition, Lief. 8. St. Petersburg.

S chwe ndener, S., 1894. Zur Wachstumsgeschichte der Rivularien. Sitzungsber. Kgl. preuss. Akad. Wiss., XXXVIII. Berlin.

S k u j a, H., 1926. Vorarbeiten zu einer Algenílora von Lettland, II. Act. Hort. Bot. Univ. Latv., I, 3. Riga.

S mith, G. M., 1920. Phytoplankton of the Inland Lakes of Wisconsin, I. Bull. Wisc. Geol. a. Nat.-Hist. Surw., No. 57, Scient. ser. 12. Madison.

T e od oresco, E. C., 1907. Matériaux pour la flore algologique de la Roumaine. Beih. z. Bot. Zentralbl., 21. 2. Dresden.

D e T o n i, G., 1939. Noterelle di nomenclatura algologica, IX. Archivo Botanico, XV, 3-4 (Nuova Serie, vol. 5). Forli.

В оронихин Н. Н., 1935. Водоросли и их группировки в озерах Имандра и Нотозеро (Кольский полуостров). Тр. Бот. инст. АН СССР, сер. II, 2. М.-Л.

Голл ер бах М. М., Полянский В. И., 1951. Определитель пресноводных водорослей СССР. Вып. І. Москва.

Г о р бун о в а Н. П., 1949. Наблюдения по цитологии и истории развития некоторых синезеленых водорослей. Автореферат диссертации на соискание ученой степени кандидата биологических наук. Москва.

Г ор б у но в а Н. П., 1950. Наблюдения по цитологии и историн развития некоторых синезеленых водорослей. Бюлл. Моск. о-ва исп. прир., отд. биол., вып. 3. Москва.

Елен к и н А. А., 1949. Синезеленые водоросли СССР. Специальная (систематическая) часть. М.-Л.

И в а н о в Л. А., 1899. Материалы по флоре водорослей (ехcl. Diatomeae) Московской губернии. Bull. Soc. Imp. Nat. de Moscou, n. sér., vol. 12. Moscou.

И в анов Л. А., 1901. Наблюдения над водной растительностью озерной области. Тр. Бородинск. биол. ст. в Карелии I, СПБ.

К иселе в И. А., 1927. Новые данные о водорослях Аральского моря. Изв. Отд. прикл. ихтиол. и научн.-пром. иссл., $\mathrm{V}, 2$. Ленинград.

К и сел е в И. А., 1931а. Опыт гидробиологической характеристики типовых водоёмов Ср. Азин. Тр. Ср.-аз. гос. унив., сер. XIIa, География, вып. 9. Ташкент.

К и сел е в И. А., 1931b. Состав и распределение фитопланктона в Амурском лимане. Иссл. морей СССР. Гос. гидрол. инст,, вып. 14. Ленинград.

М ей е р К. И., 1922. Материалы по флоре водорослей оз. Байкала. Журн. Моск. отд-а Русск. бот. о-ва, І. Москва.

М е й е р К. И., 1930. Введение во флору оз. Байкала. Бюлл. Моск. о-ва исп. прир., XXXIX, '3-4. Москва.

М ей ер К. И. и Рейнга рд т. В., 1925. К флоре водорослей оз. Байкала и Забайкалья. Бюлл. Моск. о-ва исп. прир., XXXIII, 3-4. Москва.

П ол я н с к и й В. И., 1930. К вопросу о стадиях развития Gloeotrichia natans (Hedw.) Rabenh. Изд. Гл. Бот. сада СССР, XXIX, 3-4. Л.

Полян яский В. И., 1935. Фитопланктон Прозоловского водоёма. Уч. зап. ЛГУ, сер. биол., том I, вып. І. Л.

С тр ог а н в С. Н. и 3 а х а ров Н. Г., 1927. Волга, Ока и Москва-река в качестве источников водоснабжения г. Москвы. Тр. Комиссии по изыск. нов. ист. водоснабж. г. Москвы, вып. 3. Москва.

Ш кор батов Л. А., 1926. Гидробиологическое изучение микрофлоры реки Сев. Донца и его притоков Уд и Лопань. Тр. Комиссии по сан.-биол. обслед. Сев. Донца и его притоков, вып. I. Харьков.

Tartu Riiklik olikool

Saabus toimetusse

14. XI 1957 


\title{
О СТАДИЯХ РАЗВИТИЯ ВИДОВ GLOEOTRICHIA J. AG. \\ В СВЯЗИ С СИСТЕМАТИЧЕСКИМ ПОЛОЖЕНИЕМ OSCILLATORIA LACUSTRIS (KLEB.) GEITL.
}

\author{
Э. Г. Кукк
}

\section{Резюме}

На основе наблюдений, проведенных на культурах Gloeotrichia pisum (Ag.) Thur., а также сравнения литературных данных и исследования материалов, собранных из различных водоемов Әстонской ССР, автор приходит к выводу, что существовавший до сих пор вид Oscillatoria lacustris (Kleb.) Geitl. (синонимы: Trichodesmium lacustre Kleb., Trichodesmium Iwanoffianum Nyg.) не является настоящим видом, а представляет собой молодую стадию произрастающих спор какого-то вида (или видов) рода Gloeotrichia. Множество описанных форм названного материала в литературе зависит от того, что в проросших спорах изменения происходят в течение небольшого піромежутка времени, причем в начале эти изменения протекают у всех видов рода Gloeotrichia почти одинаково, в поздних же стадиях, в зависимости от вида, по-разному (Горбунова, 1949, 1950; Schwendener, 1894; Beck, 1886).

Тартуский государственный университет

Поступила в редакцию 14 XI 1957

\section{OBER DIE ENTWICKLUNGSSTADIEN DER ARTEN GLOEOTRICHIA J. AG. IM ZUSAMMENHANG MIT DER SYSTEMATISCHEN LAGE DER OSCILLATORIA LACUSTRIS (KLEB.) GEITL.}

\section{E. Kukk}

\section{Zusammenfassung}

Auf Grund der Beobachtungen über die in den Kulturen aufgezüchteten Gloeotrichia pisum (Ag.) Thur. und des Vergleichens der entsprechenden Literaturangaben, sowie der Erforschung aus verschiedenen estländischen Gewässern gesammelter Materialien, kommt der Verfasser zum Schluss, dass die bis heute für eine selbständige Art gehaltene Oscillatoria lacustris (Kleb.) Geitl. keine eigene Species, sondern einfach gekeimte Dauerzellen einer Art (oder Arten) der Gattung Gloeotrichia darstellt. Die grosse Menge der bisher beschriebenen verschiedenen Formen ergibt sich daraus, dass die Veränderungen nach der Keimung der Sporohormogonien sich in verhältnismässig kurzer Zeit abspielen. Anfangs stellen sich die Veränderungen bei allen Arten der Gattung Gloeotrichia gleichmässig dar, aber in späteren Entwicklungsstadien schlagen sie bald verschiedene Wege ein (Горбунова, 1949, 1950; Schwendener, 1894; Beck, 1886). 